\title{
Frege on Truths, Truth and the True
}

\author{
Wolfgang Künne \\ Department of Philosophy, University of Hamburg
}

The founder of modern logic and grandfather of analytic philosophy was 70 years old when he published his paper Der Gedanke (The Thought) in 1918. This essay contains some of Gottlob Frege's deepest and most provocative reflections on the concept of truth, and it will play a prominent role in my lectures. The plan for my lectures is as follows. What is it that is (primarily) true or false? 'Thoughts', is Frege's answer. In $\S_{1}$, I shall explain and defend this answer. In $\S_{2}$, I shall briefly consider his enthymematic argument for the conclusion that the word 'true' resists any attempt at defining it. In $\$_{3}$, I shall discuss his thesis that the thought that things are thus and so is identical with the thought that it is true that things are thus and so. The reasons we are offered for this thesis will be found wanting. In $\$ 4$, I shall comment extensively on Frege's claim that, in a non-formal language like the one I am currently trying to speak, we can say whatever we want to say without ever using the word 'true' or any of its synonyms. I will reject the propositional-redundancy claim, endorse the assertive-redundancy claim and deny the connection Frege ascribes to them. In his classic 1892 paper Über Sinn und Bedeutung (On Sense and Signification) Frege argues that truth-values are objects. In $\$ 5$, I shall scrutinize his argument. In $\$ 6$, I will show that in Frege's ideography (Begriffsschrift) truth, far from being redundant, is omnipresent. The final $\$_{7}$ is again on truth-bearers, this time as a topic in the theory of intentionality and in metaphysics. In the course of discussing Frege's views on the objecthood, the objectivity of thoughts and the timelessness of truth(s), I will plead for a somewhat mitigated Platonism.

Keywords: truth-bearers, truth-values, timelessness

Corresponding author's address: Wolfgang Künne, Eichengrund 30, D-22589 Hamburg, Germany. Email: wolfgang.kuenne@uni-hamburg.de.

This is a revised version of the text of the Gottlob Frege Lectures I delivered in Tartu in 2006. I have profited a lot, or so I hope, from the lively discussions that followed my talks. The somewhat indecent frequency of my references to Conceptions of Truth is due to the fact that my lectures had been preceded by a seminar on my book. 


\section{Truth-Bearers}

What is susceptible of truth and falsity? Suppose Ann tells us, 'Last summer I spent my holidays in Estonia. We talk ordinarily and readily enough of, e.g., What Ann said; of its being believed or doubted by Ben; of Cindy denying $i t$; of Douglas saying the same thing, though in different words; of its being more melodiously expressed in Italian by Emanuela; and of its being true (or false). On the face of it, the noun-phrases and attendant pronouns here do not refer to the token words, the token sentence, which Ann uttered; or, indeed, to the type-sentence of which she uttered a token; or even to the meaning of that sentence, since the same type-sentence, with constant meaning, can be used to say different things with different truth-values. Frege calls the one thing that can be believed and stated and that may be true or false a thought. (Many other philosophers, including the author of $C T$, use the word 'proposition' with the same intent.)

But does not Frege identify the thought expressed by an utterance with the meaning of the sentence uttered? No, he does not. But let us postpone this issue for a moment and consider a different question that is too seldom asked in the literature on Frege: What does he take sentences to be? He writes:

(F.1) What is it that we call a sentence [Satz]? A series of sounds [eine Folge von Lauten], but only if it has a sense [Sinn] (this is not meant to convey that any series of sounds that has a sense is a sentence). [...] $(\mathrm{Ged}, 60)$

So, by Frege's lights, a sentence is not a type-sentence, something that can be both uttered and inscribed again and again. It is not an abstract linguistic entity like the one I am talking about when I say, 'This morning I have read this sentence in three different newspapers, and by now I have heard it at least four times on the radio.' Rather, sentences are sentence-tokens, they are concrete rather than abstract, particulars rather than universals. Furthermore, Frege assigns priority to audible tokens as opposed to visible tokens, inscriptions. Basically, he maintains, an inscription is "a direction for forming a spoken sentence in a language in which series of sounds serve as signs for expressing a sense" $(N, 280(260)) .{ }^{1}$ In this respect Frege follows Aristotle's footsteps, perhaps unwittingly (De Int. 1): Inscriptions ( $\tau \alpha \gamma \rho \alpha \phi o \mu \epsilon v \alpha)$ are symbols for utterances $(\tau \alpha \epsilon v \tau \eta \phi \omega v \eta)$. Frege continues:

(F.2) And when we call a sentence true we really mean that its sense is true [Und wenn wir einen Satz wahr nennen, meinen wir eigentlich

\footnotetext{
1 The bracketed reference is to the English translation of $N$.
} 
seinen Sinn.] Hence it is only the sense of a sentence for which the question of truth can arise at all. (loc.cit.)

In his 1918 paper Frege does not argue for his contention that we mean the sense of a sentence $S$ when we call $S$ true. But in a precursor of this paper he did:

(F.3) For, on the one hand, [1] the truth of a sentence is preserved when it is correctly translated into another language, and, on the other hand, [2] it is at least conceivable that the same series of sounds should have a true sense in one language and a false sense in another. $(N, 141$ (129))

As far as the first argument goes, it is equally plausible in the intra-lingual case as it is in the inter-lingual case. Whether we move from English, 'A viola is larger than a violin', to German, 'Eine Viola ist größer als eine Violine', or whether we move from the latter sentence to a synonymous sentence in German, 'Eine Bratsche ist größer als eine Geige, "truth is preserved". But one might object that this does not yet show that these three utterances express one and the same truth.-Frege's second argument, too, is equally plausible in the intra-lingual case as it is in the inter-lingual case. The series of sounds 'One billion is one thousand million' expresses a truth in American English and a falsehood in real English, so what Frege declares to be conceivable is actually the case, and of course, an utterance of an ambiguous English sentence ('Some people have never seen a bank') may express a truth under one reading and a falsehood under another reading. But one might object that this only shows that the outcome of the truth-evaluation of an utterance depends on the sense assigned to it, but it does not yet show that what is true or false is not the utterance but rather its sense. Why not say that the utterance, as its speaker wants it to be understood, is true or false, as the case may be?

Well, first of all, this will not work in all cases. The scene is set in Milano, in pre-Euro times. Annabella, a business woman, has two telephones on her desk. One day an American colleague and a British friend rang her simultaneously wanting to know how much profit her firm has made last year. She wanted only her friend to know the truth. So picking up both receivers she said, 'One billion lira. But excuse me, I have a visitor in my office. Let us talk tomorrow.' And then she hung up. Annabella intended her American colleague to understand that the profit amounted to $10^{9}$ lira, and her British friend to understand that the profit amounted to $10^{12}$ lira. A falsehood and a truth were meant to be conveyed by just one utterance. But why not say that the utterance, as Annabella wanted it to be understood by her British 
addressee, is true, and that her utterance, as she wanted it to be understood by her American addressee, is false?

Note how the objector is piling relativizations. If the series of sounds, the vehicle of the message, were a truth-value bearer it would be both true and not true, which is certainly unbearable. So we are bound to take a deeper breath and say that the utterance is true relative to a certain interpretation and not true relative to another interpretation. An utterance cannot be called true, full-stop, or false, full-stop. But the primary use of 'true' and 'false' does not stand in need of any relativization. The thing that is simpliciter true or simpliciter false, true or false without relativization to anything, is the thought expressed. The case of Annabella shows that one and the same utterance can serve to express both something that is true, full-stop, and something that is false, full-stop.

There is no need for relativization to possible worlds, since something is simpliciter true just in case it is true with respect to the actual world. So, whatever is false with respect to the actual world, though true with respect to some possible world, is simpliciter false. (As for the modal operators, Frege adopts a Kantian stance. "The modality of judgements", Kant wrote in his first Critique, "is a quite peculiar function. Its distinguishing characteristic is that it contributes nothing to the content of the judgement ... but concerns only the value of the copula in relation to thought in general" ( $K r V, \mathrm{~B} 100)$. In $B S, \$_{4}$, Frege endorses the negative half of this claim, and he tries to clarify its opaque second half. An utterance of 'Necessarily, $p$ ' expresses the thought that $p$, nothing more and nothing less, but its speaker also indicates that she takes it to be certain that $p$. An utterance of 'Possibly, $p$ ' also expresses nothing but the thought that $p$, but its speaker also indicates that he takes it not to be certain that $\sim p$.)

Admittedly, often when a speaker says, 'That is true', she points, as it were, at an utterance she just heard. But from this it does not follow that she ascribes truth to that utterance. Pointing at a picture on the wall, you might truly say, 'That is a former president of the college,' although fortunately the honourable gentleman is not himself hanging on the wall. From the fact that you are pointing at the picture it does not follow that you ascribe the property of being a former president of the college to that picture. Suppose, somebody makes an assertion by uttering sentence $S$, and you concede, 'That is true, but .... Some time later you are annoyed by another assertoric utterance of $S$, and you reply wearily, 'As I said half an hour ago, that is true, but ...' This rejoinder is absolutely correct: you did twice ascribe truth to one and the same "thing". So what is called 'true' in your comments is not a datable speech episode. Pointing at a picture on the wall you refer to something else, sc. to the person that is depicted there. Pointing to an utterance, you refer 
to something else, sc. to what is expressed by that utterance. In both cases the object referred to is picked out by an act of (what Quine calls) deferred ostension.

By identifying the thought expressed by an utterance with the sense of the utterance, Frege does not identify the thought expressed by an utterance with the meaning of the sentence uttered. Here is one reason: It is the utterance of a sentence which is the primary bearer of sense, not the type-sentence that is uttered, whereas it is the sentence uttered which is the primary bearer of conventional linguistic meaning, that is, of lexicogrammatical meaning. (A dictionary provides you with information about a type-word, not about the inscription of that type-word you are staring at on the pertinent page.) Here is another reason: Take a sentence that is neither lexically nor syntactically ambiguous, 'Today is Monday'. This sentence does not change its conventional linguistic meaning from one day to the next, but if you utter it on a Monday you express a truth, whereas you will no longer do so when you utter it on the next day. Or take the lexico-grammatically unambiguous sentence 'This ship is the same as this'. Imagine three utterances of this sentence, in each of them the first two words are used to pick out the same ship, but the first utterance expresses a trivial truth, the second an informative truth, and the third a falsehood. So, the Fregean sense of an utterance containing indexicals or demonstratives is not the lexicogrammatical meaning of the sentence uttered.

Does this identity obtain if the sentence uttered is free of context-sensitive elements? No, it does not. If somebody says, 'Many Boches spend their holidays in Italy', or 'There are many niggers in Brooklyn', the same thoughts would have been expressed if he had said, 'There are many Negroes in Brooklyn', and 'Many Germans spend their holidays in Italy', but in using the derogatory terms the speaker betrays a less than friendly attitude towards certain people. Like all such differences in what Frege calls tone or colouration this makes for a difference in lexical meaning that ought to be preserved in a good translation. Furthermore, a sentence may contain a word that can be deleted without affecting the thought that is expressed by an utterance of that sentence, but the conventional linguistic meaning of the sentences is affected by its deletion. ${ }^{2}$ Consider the beginning of Faust's monologue, "I've studied, alas, philosophy, jurisprudence, medicine,.... Elimination of the interjection 'alas' would not affect the identity of the thought expressed. This word does not have a Fregean sense, any more than the sound of the speaker's voice by means of which he might convey what 'alas' is used to convey has such a sense. So it does not contribute anything to the thought that is expressed. An expression may lack sense without lacking conventional linguistic meaning:

${ }^{2}$ Cf. Ged, 63-4; N, 152 (140). 
after all, 'alas' means the same as 'ach' in Goethe's original. The same holds, mutatis mutatis, for the word 'yet' in 'Ann is ill, and yet she is in a very good mood': if it were eliminated the thought expressed would still be the same, but the linguistic meaning would be different.

Is the Fregean sense of an utterance perhaps identical with the lexicogrammatical meaning of the sentence uttered, if the sentences is free from context-sensitive elements as well as free from colouration? As we shall see, Frege's views on truth imply that sometimes sense and meaning diverge even if these two conditions are met.

When I wrote my book I thought I had hit upon an argument which demonstrates that the conventional linguistic meaning of a sentence should never be identified with the thought (or proposition) expressed by an utterance of that sentence. The argument, which is due to Richard Cartwright, runs as follows (Künne 2005, 372):

What Ann said or thought may be plausible or implausible, remarkable or trivial, well-supported or completely unsubstantiated, but a sentential meaning does not have any of these virtues or vices. What Ben thought or said may be confirmed or repudiated, endorsed or challenged, it may be universally acknowledged or contradicted in some quarters, but no sentence-meaning ever undergoes any of these vicissitudes. What is said in an utterance of a sentence has ever so many properties which are not shared by the meaning of the sentence uttered even if the sentence is stable [that is, free from contextsensitive elements, and I now add, from colouration]. Hence, by Leibniz’s Law, propositions are not sentential meanings.

Leibniz's Law is the principle that

(LL) For all $x$, for all $y$, if $x$ is identical with $y$, then $x$ is-or-does whatever $y$ is-or-does and vice versa.

At a later point I shall say a bit about the second quantifier in the formal rendering of this:

$$
\left(\mathrm{LL}^{*}\right) \forall x \forall y(x=y \rightarrow \forall \phi(\phi x \longleftrightarrow \phi y))
$$

Here is an example in which the invocation of this principle, or more directly, the invocation of what you get from (LL) by contraposition, is certainly justified:

(1) The author of Der Gedanke is German,

(2) The author of the Tractatus is not German. So, by LL,

(3) The author of Der Gedanke * the author of the Tractatus. 
Now it very much looks as if the Cartwright-Künne argument, where ' $S$ ' can be replaced by any declarative sentence, runs along the same lines:

(A) The thought expressed by Ann's utterance of $S$ is extremely implausible.

(B) The meaning of $S$ is not extremely implausible. So, by LL,

(C) The thought expressed by Ann's utterance of $S \neq$ the meaning of $S$.

But now reflect on the following scenario: You are a tourist visiting Windsor Castle. At a distance you dimly see an animal on the lawn, you cannot recognize it for what it is, but then you hear it bark, and you strongly dislike its barking. This gives us your 1st premiss:

$(\alpha)$ The animal I saw on that lawn is a cur.

Your 2nd premiss is a statement you make on the basis of hear-say and of prejudice:

( $\beta$ ) The Queen's pet animal is not a cur (but a dog).

Does Leibniz's Law now justify the following conclusion?

$(\gamma)$ The animal I saw on that lawn $\neq$ the Queen's pet animal.

Hopefully not, for as it so happens, the animal you saw on that lawn is the Queen's pet. The second premiss does not express the negation of the thought that the Queen's pet animal is a cur. Rather, in uttering $(\beta)$ you indicate that you are not prepared to use such derogatory terms in talking about Her Majesty's dog. In uttering $(\beta)$ you distance yourself from the colouration of 'The Queen's pet animal is a cur', not from the thought it expresses. In natural languages what looks like the formulation of the negation of a thought often is not really anything of the sort. 'This pizza is not large, it is huge', Ann says. Her first utterance does not express the negation of the thought that the pertinent pizza is large, for if it did Ann's utterance would be inconsistent. After all, whatever is huge is a fortiori large. By inserting a 'not' in 'This pizza is large' Ann distances herself from a claim that she finds too weak, not from a claim she regards as false. When a teacher corrects a child's grammatical mistake by saying, 'You did not see two gooses, you saw two geese', the teacher's first utterance does not express the negation of the thought expressed by 'You saw two gooses', for this pseudo-sentence does not express any thought whatsoever.

Back to the Cartwright-Künne argument. Its invocation of Leibniz's Law is only legitimate if the 'not' in premiss (B) does the contradictory-forming 
job of the negation operator. But perhaps in (B) it is rather an indicator of one's disapproval of a certain way of talking. To be sure, talk of "implausible (well-supported, completely unsubstantiated) meanings" sounds odd, but a critic of the argument can object that this is just the oddity of unusual talk, not that of a glaring falsehood ${ }^{3}$. So the argument now appears to me less strong than it once did.

\section{Indefinability}

In his criticism of all attempts at defining truth Frege begins with a local argument that attacks a traditional object-based correspondence theory. That is to say, the correspondence theorists criticized by Frege take the truth of, say, the statement that the Cologne Cathedral has two spires (Frege's example) to consist in its correspondence to the Cologne Cathedral rather than to the fact that the Cologne Cathedral has two spires.

One may wonder why Frege does not engage with fact-based correspondence theories. After all, they were upheld by illustrious contemporaries in Cambridge, and it is hard to imagine that this kind of view was never touched upon when he had discussions with Wittgenstein in Jena and at the Baltic Sea. Frege must have regarded this kind of view as a non-starter in the field of correspondence theories. (F.4) "What is a fact?", he asks (Ged, 74), and his answer is, "a fact is a thought that is true". For a correspondence theorist what a truth-bearer corresponds to has got to be distinct from the truth-bearer. Of course, the Cantabrigians would have rejected Frege's identification of facts with truths. But there has been a heated debate about whether they, or their latter-day Australian followers, ever succeeded in preventing facts from collapsing into one. From a Fregean point of view, the Gödel-Church argument, known under the nickname 'the Slingshot', is an attempt at showing that if you believe in a plurality of facts you would better identify them with true thoughts.)

I shall put Frege's local argument against object-based correspondence theories aside here, for it raises a host of exegetical issues. Let us focus instead on his subsequent global argument according to which no explanation of the concept of truth is adequate:

(F.5) And any other attempt also breaks down. For [1] in a definition one would specify certain marks (Merkmale). And [2] when applying it to a particular case, the point at issue would always be whether it were true that those marks were exemplified. So [3] one would be going round in a circle. Hence [4] it seems likely

${ }^{3}$ Schnieder (2004). 
that the content of the word 'true' is sui generis and indefinable (ganz einzigartig und undefinierbar). (Ged, 60)

Many commentators have misconstrued this objection as a vicious infinite regress argument. [3] makes it as clear as can be that Frege takes himself to be offering a kind of vicious circle objection. This does not mean that he condemns all definitions of 'true' as circular definitions. A definition is circular if the concept expressed by the definiendum is (openly or covertly) expressed by a proper part of the alleged definiens. Thus 'For all $x, x$ rotates iff $x$ moves around the axis of $x$ ' is a covertly circular definition, for what does 'the axis of $x$ ' mean if not: the line around which $\mathrm{x}$ rotates or might rotate? The circle Frege is complaining of is not of this kind. Rather, it is a circle one gets into as soon as one tries to apply the alleged definiens of 'true'.

Unfortunately, as it stands the argument is enthymematic. So one must try to find the missing premisse(s) acceptance of which can reasonably be ascribed to Frege. The definitions referred to in [1] are not what Frege calls constructive (aufbauend) or stipulative definitions. Such a definition either introduces a new expression for purposes of abbreviation (such as 'pi-meson' in physics) or forces an old expression into a new tightly circumscribed service (e.g., 'model' in mathematics). No philosopher who tries to define 'true' is aiming to graft a new meaning upon this old word. The definitions at issue are rather dissecting (zerlegend) or analytic definitions which purport to capture, by means of a compound expression, the sense of an atomic expression already in use.

Now according to Frege's technical use of the term 'mark', $\mathrm{M}$ is a mark of the concept expressed by a predicate $\mathrm{P}$ just in case the following conditions are satisfied: $M$ is a concept, $M$ is expressed by a component of an analytic definition of $\mathrm{P}$, and nothing can fall under the concept expressed by $\mathrm{P}$ without falling under $\mathrm{M}$. This condition is met if and only if the definiens of $\mathrm{P}$ is conjunctive. Thus, in virtue of the definition 'For all $x, x$ is a drake iff ( $x$ is a duck, and $x$ is male)', the concepts expressed by 'male' and by 'duck' are marks of the concept expressed by 'drake. Such a definition pays epistemic dividends, for it allows us to answer the question whether the definiens applies to an object via answering two simpler questions. Now Frege cannot reasonably assume that each and every candidate for a definiens of 'true' has the structure of a conjunction. The very definition he had been concerned with in his local argument, 'For all $x, x$ is true iff $x$ corresponds with reality', lacked this kind of structure. So his use of the term 'marks' in [1] cannot be the technical one of his earlier work. In [1] it cannot amount to more than to the reasonable requirement that the alleged definiens is not atomic (unlike that in 'For all $x, x$ is a serpent iff $x$ is a snake').

But according to Frege one feature of conjunctive analytic definitions is 
shared by all adequate analytic definitions: they capture an order of epistemic priority,-we come to know that the definiendum applies to an object through coming to know that the definiens applies to it. Consequently, a candidate for the title of an analytic definition of a predicate $\mathrm{P}$ is to be rejected if having the concept expressed by $\mathrm{P}$ is a precondition for deciding whether the alleged definiens applies in any given case. If we now assume, as Frege does in [2], that one cannot decide whether the characteristics specified in an alleged definiens of 'true' are exemplified in a given case without deciding whether it is true that they are exemplified, the conclusion in [3] follows, for one can hardly decide whether something is thus and so (e.g., true) without having the concept of a thing's being thus and so (of a thing's being true).

Thus understood, Frege's argument crucially depends on the assumption that one cannot decide whether the characteristics specified in an alleged definiens of 'true' are exemplified in a given case without deciding whether it is true that they are exemplified. This assumption is an instance of a more general principle, which Frege seems to regard as self-evident:

(Decide) One cannot decide whether things are thus and so without deciding whether it is true that things are thus and so.

In the next section we will see why Frege finds this obvious. It is noteworthy, though seldom noted, that Frege's phrasing in (F.5) [4], "it seems likely that

...", betokens that he himself does not regard the argument that precedes it as a watertight proof of his indefinability thesis.

\section{The Identity Thesis}

Already in his 1892 paper Über Sinn und Bedeutung (34b), Frege maintained that the sentence 'The thought that 5 is a prime number is true' expresses the same thought as the simple ' 5 is a prime number'. He kept on repeating this kind of identity claim, using various examples: thus in his 1897 manuscript 'Logic' the Prussian reminiscence 'Frederick the Great won the battle of Rossbach' $(N, 153,(141))$ serves the same purpose, and in Ged it is a report of an irenic summery impression:

(F.6) It is also worth noticing that [1] 'I smell the scent of violets' has just the same content as 'It is true that I smell the scent of violets'. So it seems that [2] nothing is added to the thought by my ascribing to it the property of truth. [...] (Ged, 61c (6))

As regards the mathematical sentence, we are told that inserting it in what I shall call the truth frame 'The thought that ( ) is true' makes no difference to the thought expressed. As regards examples like that in [1], we are told that 
applying what I shall call the truth prologue 'It is true that ( )' to them does not affect the identity of the thought expressed. So apparently the syntactical difference between frame and prologue are deemed to be irrelevant. Surely, all this is meant to generalize. Frege subscribes to the following identity thesis:

(IDENTITY) Replace the sentence letter by any declarative sentence you like, 'It is true that $p$ ' and '(The thought) that $p$ is true' express the same thought as the plain ' $p$ '.

I have taken the liberty of inserting the brackets into the truth frame, for the identity thesis will have a greater chance of being correct if we delete this noun-phrase. Otherwise somebody might object: Look, 'Snow is white' does not formally imply 'There is at least one thought', whereas this is formally implied by 'The thought that snow is white is true'. So how can they express the same thought?

One consequence of the identity thesis jumps into the eye: sense and conventional linguistic meaning can diverge even if context-sensitivity and colouration are absent. The lexico-grammatical meaning of 'It is true that 5 is prime' certainly differs from that of ' 5 is prime', but Frege wants us to believe that their utterances express the same thought, have the same sense.

Unlike colouring words like 'alas' and 'yet', the truth connectives do have a sense, but Frege ascribes to their sense a truly remarkable property:

(F.7) The word 'true' has a sense that contributes nothing to the sense of the whole sentence in which it occurs as a predicate. $(N, 272$ (252))

This formulation is a bit careless: firstly, because the word 'true' is not a predicate but a general term, and secondly, because Frege's claim can at best hold of the truth connectives. So the contention can only be that it is their sense which annihilates itself, as it were: they have a sense that makes no contribution to the thoughts expressed by sentences containing them. In the third of his 'Logical Investigations', entitled 'Compound Thoughts' (1923), Frege maintains that 'It is not the case that 5 is not prime' has the same sense as ' 5 is prime. ${ }^{4}$ Here, too, the idea seems to be that the sense of the operator 'It is not the case that ...not ...' is self-effacing: this operator has a sense that contributes nothing to the thought expressed by the whole sentence of which it is a part. No wonder Davidson once nicknamed the redundancy theory of truth 'the double-negation theory of truth.'

Note that Frege's identity thesis is stronger than the equivalence claim that all instances of the following biconditional schemata express truths:

${ }^{4} \mathrm{Ggf}, 44$

5 Davidson $(1984,38)$ 
(Equivalence ${ }_{1}$ ) It is true that $p$, if and only if $p$

(Equivalence $)_{2}$ ) That $p$ is true if and only if $p$.

The comma in (Equivalence ${ }_{1}$ ), almost universally forgotten, serves syntactical disambiguation. If you accept the identity thesis you should also endorse the equivalence claim, but in the opposite direction there is no such obligation: you can consistently deny that instances of ' $p$ ' and 'it is true that $p$ ' ever express the same thought while accepting instances of 'It is true that $p$, if and only if $p$ '. Frege's identity thesis entails, whereas the equivalence claim does not entail, that all substitution-instances of the following schema come out true:

(Act) One cannot VERB that / whether $p$, without thereby VERB-ing that / whether it is true that $p$.

The capitalized dummy in (Act) can be replaced by verbs that are used in ascriptions of propositional mental acts-or-attitudes, such as 'judge', 'believe' and 'wonder', as well as by verbs that are used in reports of propositional speech acts, such as 'assert', 'swear' and 'ask'. (A structurally similar claim can be found in Hume: "Whatever we conceive, we conceive to be existent". ${ }^{6}$ ) Obviously, 'decide' belongs to the former group, so (Decide), the principle Frege tacitly appealed to in his argument for indefinability, is a substitutioninstance of schema (Act).

In (Künne 2005, 226-236), I have argued that Frege's identity thesis should not be confused with its disquotational counterpart

$\left(\right.$ IDENTITY $\left.^{\star}\right)$ Replace the sentence letter by any declarative sentence you like, " $p$ ' is true" expresses the same thought as the plain 'p'.

The disquotational identity thesis is just false. Let me repeat my Argument From Doxastic Difference. Compare

(T) 'Snow is white' is true

(S) Snow is white

and pretend that sentences can without any further ado be called 'true.' If these sentences were to express the same thought nobody could believe what either of them expresses without eo ipso believing what the other expresses. But a monoglot Estonian who believes that snow is white may not believe

6 Treatise, I, 2, \$6; cp. I, 3, \$6 
that the English sentence 'Snow is white' is true, and if a monoglot Estonian with defective eye-sight believes that snow is bluish but takes my word for it that the English sentence is true, then he believes the sentence to be true without believing snow to be white. Hence (S) and (T) do not express the same thought. You cannot use an Argument From Doxastic Difference against Frege's identity thesis. Replace $(\mathrm{T})$ by

(U) It is true that snow is white.

The claim that somebody might believe that $\mathrm{U}$ without believing $\mathrm{S}$ would be obviously false, and the reverse claim that somebody might believe that $S$ without believing $U$ would just be a flat denial of (Act).

If Frege's partial criterion of identity for thoughts is adequate, then his identity thesis can be justified by appeal to this criterion. Let me begin by presenting the key notion in Frege's criterion. From a manuscript of 1906 one can extract a definition of a relation between sentences which Frege, somewhat misleadingly, calls equipollence and which I prefer to call Cognitive Equivalence (F.8): ${ }^{7}$

(CE) Two sentences are cognitively equivalent if and only if nobody who fully understands both can assent to one of them without immediately being ready to assent to the other as well.

Dummett once maintained that (for a long time) Frege regarded cognitive equivalence "as a sufficient as well as necessary condition for identity of sense". But if cognitive equivalence were to guarantee identity of thought, Frege would have to swallow some intuitively bizarre consequences which are certainly not acceptable to him. The sentences 'A rose is a rose' and 'Nothing is larger than itself' are cognitively equivalent, since the content of either sentence is such that (to use Frege's own words) "it would have to be immediately accepted as true by anyone who had grasped it properly." 9

7 Frege writes

(F.8) "Two sentences A and B can stand in such a relation that anyone who accepts the content of $A$ as true must straightaway accept the content of $B$ as true, and conversely, that anyone who accepts the content of $\mathrm{B}$ as true must immediately accept that of $\mathrm{A}$ as true (equipollence). It is here being assumed that there is no difficulty in grasping the content of A and B ..." (N, 213 (197)).

'Equipollence' is standardly used in the sense of 'logical equivalence', and clearly sentences that are logically equivalent do not always comply with the condition Frege outlines.

8 Dummett (1991b, 171); cf. his Dummett (1991a, 294, 298, 301); Dummett (1993, 99). He no longer maintains this: see Dummett $(1997,247-248)$

9 Timothy Williamson has argued in his Williamson (2006) that no logical truth and no sentence which can by exchange of synonyms be transformed into a logical truth is such 
Hence if cognitive equivalence were a sufficient condition of sameness of thought, then our two sentences would express the same thought. All sentences the contents of which simply defy disbelief would express one and the same thought. In other words, there would be only one thought that is "self-evident (unmittelbar einleuchtend)". ${ }^{10}$ Surely Frege's conception of an axiom does not allow him to accept this result. Furthermore, any conjunction one conjunct of which expresses a self-evident truth would express the same thought as the other conjunct by itself, e.g.

(A) The moon is round

(B1) The moon is round, and nothing is larger than itself.

None of these consequences are forthcoming if Frege takes cognitive equivalence only to be a necessary condition for identity of thought. And so he does, and like many others I follow suit.

We can gather what Frege regards as a Sufficient Identity Condition from the very same manuscript from which I culled $C E$ (F.9): ${ }^{11}$

that one cannot understand it without straightaway being ready to assent to it. (Obviously, Williamson regards sentences as truth-value bearers.) Even if his argument were sound it would not justify his conclusion that "there is no conceptual truth". His argument depends on finding or inventing some relevant form of logical unorthodoxy. One gathers that this will be a difficult feat in the case of instances of 'If $p$ and $q$, then $q$ '. But in any case, no logical unorthodoxy can undermine a competent speaker's readiness to assent to 'Nothing is larger than itself', for this sentence does not belong to either of the two categories Williamson considers. But it seems that logical unorthodoxy can undermine a speaker's readiness to assent to (a), 'Socrates is wise', once she has assented to (b), 'It is not the case that Socrates is not wise.' (To prevent distraction by other problems, let us assume that Socrates is one of our contemporaries.) For Frege and all adherents of classical logic, every instance of 'If $\sim \sim p$, then $p$ ' expresses a truth, whereas intuitionist logicians contest that. At least in mathematics, they maintain, a statement $X$ is stronger than its double negation, because, so they argue, a proof of the latter is a proof that one cannot disprove $X$, and that does not amount to a proof of $X$. Would an advocate of intuitionist logic, who took this to be a reason for withholding assent from (a) after having assented to (b), thereby show that he does not fully understand at least one of these sentences? Is his understanding somewhat impaired by "Dutch" indoctrination? One can deny this without simply giving up the claim that (a) and (b) are cognitively equivalent. If one takes classical and intuitionist logicians to understand 'not' differently, one can maintain that (1c) is cognitively equivalent with (a) under the former reading of 'not'.

${ }_{10}^{10} 1914$ b, $242(224)$.

${ }^{11}$ Frege writes

(F.9) “...I assume that there is nothing in the content of either of the two equipollent sentences ... that would have to be at once immediately accepted as true by anyone who had grasped it properly ... [The thought expressed] is the same in equipollent sentences of the kind given above ( $N$, 213-4 (197-8), my italics). 
(SIC) Two sentences express the same thought if

(i) they are cognitively equivalent, $\wedge$

(ii) neither of them is, or contains a part which is, such that one cannot fully understand it without immediately being ready to assent to it—or without immediately being ready to dissent from it.

By adding condition (ii), up to '-,', Frege forestalls the intuitively bizarre results I pointed out. Now one would not like to say of each disjunction one disjunct of which expresses a thought that self-evidently lacks truth (e.g. (B2), 'The moon is round, or something is larger than itself') that it expresses the same thought as the other disjunct by itself. So I took the liberty of adding the dissent clause. (According to Frege, a thought can lack truth without being false. So he should allow for cases in which a thought self-evidently lacks truth although it is not false. The thought that the natural number between 5 and 6 is greater than 4 , fits this bill, and so does the thought that the round square on this blackboard is white. Consequently, we must allow for cases of dissent that do not amount to imputations of falsity.)

Unfortunately, SIC still allows for cases that should be as unwelcome as those which motivated clause (ii) and for a very similar reason. Thus

(a) Something is round

does not seem to express the same thought as $\left(b_{1}\right)$ or $\left(b_{2}\right)$ :

$\left(b_{1}\right)$ Something is round and not larger than itself

$\left(b_{2}\right)$ Something is round or larger than itself.

After all, it would be wildly implausible not to treat the pair $\left\{(a),\left(b_{1}\right)\right\}$, say, in the same way as $\left\{(\mathrm{A}),\left(\mathrm{B}_{1}\right)\right\}$. But neither $(\mathrm{b})$-sentence contains a part that is excluded by SIC(ii). This objection, which is due to Ian Rumfitt, ${ }^{13}$ may be a reason not for despair but for taking a deeper breath. After all, the (b)sentences contain an unsaturated conjunct, or disjunct, whose saturation by a non-empty singular term always results in a sentence which one cannot fully understand without immediately being ready to assent to it or to dissent from it. So such pairs could be taken care of by a third clause covering unsaturated conjuncts and disjuncts.

But let us put this complication aside. There is, of course, a price to be paid for shielding off the various odd consequences of taking cognitive

${ }^{12}$ Bermúdez $(2001,90)$ thinks that SIC(ii), up to '-', is meant to exclude logical truths. But it does not exclude all logical truths, and it does not only exclude logical truths (as witness 'Nothing is larger than itself').

${ }^{13}$ Rumfitt (1994, 609). 
equivalence by itself to be sufficient for sameness of thought: SIC is silent on sentences the content of which is, or contains a part which is, self-evidently (un)true. Never mind, SIC, if correct, suffices for justifying Frege's identity thesis.

But then, how plausible is SIC? If you accept it you have to concede not only that in the same context (1) and (2) express the same thought:

(1) On the blackboard behind me there is a diagram that is square

(2) It is true that on the blackboard behind me there is a diagram that is square,

but also that (1) and (3) have the same propositional content:

(3) Anyone who were to believe that (1) would believe something that is true.

But somebody may very well believe that (1) without believing that (3). And that should suffice by Frege's own lights for rejecting the identification of the thoughts expressed by (1) and (3), for he maintains that in a true instance of ' $N . N$. believes that p' the sentence in the that-clause can be replaced salva veritate by a sentence expressing the same thought. Or consider (1) and

(4) On the blackboard behind me there is a parallelogram that is square.

Once again, somebody may very well believe that (1) without believing that (4), and that should suffice by Frege's own lights for rejecting the identification of the thoughts expressed by (1) and (4). I conclude from this that Frege cannot convincingly defend his identity thesis by appeal to SIC.

Everybody except Davidson, ${ }^{14}$ I am inclined to think, would concede that a believer in (1) need not have mastered the concept of belief, which one needs to have in order to believe that (3). And everybody will agree that a believer in (1) need not have the concept of a parallelogram in his or her repertoire, without which one cannot believe that (4). Let me now contrast, more or less in the same way as I did in (Künne 2005, 42-52), cognitive equivalence with another relation between sentences that registers this difference:

(CB) Two sentences $s$ and $s^{\prime}$ are conceptually balanced if and only if (i) there is no concept whose mastery has to be exercised in (occurrently) understanding $s$ but not in (occurrently) understanding $s^{\prime}, \wedge$

(ii) there is no concept whose mastery has to be exercised more

\footnotetext{
${ }^{14}$ Davidson $(1984,170)$
} 
often in (occurrently) understanding $s$ than in (occurrently) understanding $s^{\prime}$.

You possess a concept, as this term is used in $C B$, if you fully understand an expression the sense of which is that concept. ${ }^{15}$ You occurrently understand the sentence 'Five is prime' only at those times at which you actually entertain the thought that five is prime, whereas you can at any time correctly be said to understand that sentence provided your English is good enough. ${ }^{16}$ Clause (ii) is meant to ensure that no cognitive balance obtains between 'Donald is a drake' and its pleonastic counterpart 'Donald is a male drake. Two sentences may be cognitively equivalent without being conceptually balanced, as witness pairs (1), (3) and (1), (4). Two sentences may be conceptually balanced without being cognitively equivalent, as witness

(5) The sun is larger than the Earth

(6) The Earth is larger than the sun.

A look at the same pair suffices to see that conceptual balance is not a sufficient condition for two sentences expressing the same thought. But, like Dummett, ${ }^{17}$ I take it that conceptual balance is a necessary condition for two sentences expressing the same thought. Now what about corresponding instances of ' $p$ ' and 'It is true that $p$ '? Are they conceptually balanced? Even if it were the case that that one cannot understand any assertoric sentence without having mastered the concept of truth (I shall confront this issue in \$6), this would not show that one has to actually exercise one's mastery of this concept when one occurrently understands, e.g., 'It is snowing.' I for one cannot see that one has to do that, and if that is not due to shortsightedness on my part, then not only do (corresponding instances of) ' $p$ ' and 'It is true that $p$ ' not express the same thought, but, because of clause (ii) of $C B$, 'It is true that $p$ ' and 'It is true that it is true that $p$ ' (etc.) do not do so either-just as Bolzano thought. ${ }^{18}$

\section{Redundancy of Truth (in English)}

Recall my last quotation from (Ged):

${ }^{15}$ In this paper 'concept' is not used in the technical way Frege uses it most of the time, i.e. as applying to functions from objects to truth-values. Most of the time, but not always: when he says in $(N, 273(253))$, 'I do not start from concepts and put them together to form a thought ... out of them; rather I come by the parts of a thought by splitting up (Zerfällung) the thought', he means by 'concept' the sense of a predicate rather than its signification (Bedeutung).

${ }^{16}$ Cf. Dummett $(1993,58-60,101-3,109,133)$.

${ }^{17}$ Dummett 1991, 295

${ }^{18}$ Cp. Bolzano (1837, vol. 2, 357, 370, 374) 
(F.6) It is also worth noticing that [1] 'I smell the scent of violets' has just the same content as 'It is true that I smell the scent of violets'. So it seems that [2] nothing is added to the thought by my ascribing to it the property of truth. [...]

The remark in [2] is a bit mysterious. After all, we never "add" anything to an object when we ascribe a property to it. (Again, a structurally similar claim can be found in Hume: "The idea of existence ..., when conjoin'd with the idea of any object, makes no addition to it". ${ }^{19}$ ) We can see what Frege is up to when we compare two sentences instantiating 'It is well known that $p$ ' and 'It is true that $p$ '. In an utterance of the former sentence, more is expressed than the thought that $p$, while in an utterance of the latter (if Frege is right) nothing more is expressed than by the plain ' $p$ '. So in [2] Frege puts forward a redundancy claim. Consider a philosophically neutral example: you would not add anything to the claim you make by uttering, 'I foretold that', if you were to say instead, 'I foretold that beforehand': the adverb is propositionally superfluous. Similarly, if Frege is right, the truth frame in '(The thought) that 5 is a prime number is true' and the truth prologue in 'It is true that I smell the scent of violets' are propositionally redundant: they do not add anything to the thoughts expressed by the embedded sentences.

Frege presents [2] as if it were a consequence of [1]. But his identity thesis cuts both ways. One can also use it to argue for the omnipresence of truth. Whatever statement I make, in making it I ascribe the property of truth to the thought expressed by my utterance. And in virtue of (Act) what holds for acts of stating holds for all propositional acts-or-states, be they mental or illocutionary: truth is present all over the place.

Truth frame and truth prologue are one-place sentence-forming operators on sentences, unary connectives like the negation operator: for one sentence as input they deliver another sentence as output. In order to save breath, I shall henceforth subsume both prologue and frame under the label 'truth-connective'. Now even if it were true that a truth-connective can always be deleted from a sentence without detriment to the thought expressed, this does not show that the predicate 'is true' is redundant. Consider the example Frege himself gives in $(\mathrm{Ged})$ when he continues, after (F.6):

(F.10) So it seems that [2] nothing is added to the thought by my ascribing to it the property of truth. [3] And yet, is it not a great result when the scientist after much hesitation and laborious researches can finally say 'My conjecture is true'? [...]

If one were to delete the truth-predicate from the scientist's exclamation in [3], the remainder would no longer express any thought, let alone the

\footnotetext{
${ }^{19}$ Treatise, I, 2, \$6.
} 
thought expressed by the non-mutilated utterance. The same holds for all unrevealing truth-ascriptions, that is, for all truth-ascriptions that do not 'reveal' (express) the thoughts for which they claim truth. Some are singular, e.g.

(S) Goldbach's Conjecture is true

or 'What Goldbach conjectured is true'. Some unrevealing truth-ascriptions are general, e.g.

(G) Whatever the Party says is true.

If things really are as (S) says they are, then some substitution instance of 'Goldbach Conjectured that $p$, and indeed $p$ ' must express a truth. But since none of us understands each and every English sentence there are instances of that schema we do not understand, hence a fortiori we do not understand their infinite disjunction. Nevertheless, we easily understand (S). Since we cannot use an infinite disjunction for saying what we want to say with (S), the equivalence of an infinite disjunction with (S) lends no support to the redundancy claim. The same hold mutatis mutandis for $(\mathrm{G})$. If things really are as $(G)$ says they are, then each conditional of the form 'If the Party says that $p$, then $p$ ' must express a truth, but for each of us there are instances of that schema we do not understand, hence a fortiori we do not understand their infinite conjunction. And yet, we easily understand (G). Once again, since we cannot use an infinite conjunction for saying what we want to say with $(G)$, the equivalence of an infinite conjunction with $(G)$ lends no support to the redundancy claim. All in all, a truth-predicate that can be employed in unrevealing truth-ascriptions, seems to be indispensable.

But can we not use the sentential quantification

$\left(S^{q}\right)$ For some $p$, Goldbach's Conjecture is (the thought) that $p$, and $p$

for saying what we want to say with (S)? Surely, Frege does not object to quantification into sentence position. (Of course, if $\left(S^{q}\right)$ were to be understood as an abbreviation for the infinite disjunction of the substitutioninstances of the open sentence to the right of the quantifier, this is no step forward.) In any case, we obtain a predicate from $\left(S^{q}\right)$ when we replace the name 'Goldbach's Conjecture' by the variable ' $x$ ', and this predicate, I would say, is a truth-predicate. (It is the very predicate by which MOD defines ' $x$ is true'. (see Künne 2005, 337) So the move to $\left(S^{\star}\right)$ does not demonstrate the dispensability of all truth predicates.

Now one would not like to conclude from this that 'true' as it occurs in (S) has a different sense than as it occurs in the revealing truth-ascription 
(R) It is true that each even number greater than 2 is the sum of two prime numbers

which expresses Goldbach's Conjecture. We can avoid this conclusion by construing the 'it' in the truth-connective cataphorically-along the lines of the 'he' in 'He was wise, the man who drank the hemlock' or the 'it' in 'It is true what Socrates said in the court'. Then (R) is just a stylistic variant of 'That each even number etc. is true', and we can now construe both in the same way as their unrevealing counterpart (S): as predications.

If we assume that all revealing truth-ascriptions are instances of the schema 'Fa', one can easily budget for the intuition that the following argument is formally valid:

(S) Goldbach's Conjecture is true.

(T) That each even number greater than 2 is the sum of two prime numbers is Goldbach's Conjecture. Therefore,

(U) That each even number greater than 2 is the sum of two prime numbers is true.

One can say that this argument exemplifies the valid argument-pattern

$\mathrm{Fa}, \mathrm{b}=\mathrm{a} \therefore \mathrm{Fb}$.

Frege himself states quite generally:

(F.11) An abstract noun-clause (abstrakter Nennsatz) [i.e. a that-clause] [can be] regarded as a noun (Nennwort), indeed one could say: as a proper name (Eigenname) of that thought as whose name it entered into the context of the compound sentence. $(S u B, 37,39)$

But he applies this only to indirect speech reports and to propositional actor-attitude ascriptions, that is, to compound sentences in which the sentence prefixed with 'that' cannot always be exchanged salva veritate by another sentence that expresses a thought with the same truth-value. Obviously, instances of 'It is true that $p$ ' or of 'That $p$ is true' are not compound sentences of this kind, for here an exchange of a truth (falsehood) by any other truth (falsehood) will leave the truth-vale of the whole unaffected. But then, the same holds for instances of 'If somebody were to believe that $p$, he or she would be right', which do contain an attitude ascription. Furthermore, truth ascriptions interact with propositional attitude reports, as witness the compound sentence

(Z) It is true that Socrates is wise, but Xanthippe does not believe it 
or the argument

(A) Plato believes that Socrates is wise, and it is true that Socrates is wise. Therefore, Plato believes at least one thing that is true.

The anaphoric pronoun in $(\mathrm{Z})$ harks back to the preceding that-clause, and what does this pronoun do if not pick up the reference of this clause? Intuitively, (A) is a formally valid argument, and just that is its regimentation as an instance of

$$
\mathrm{Fa} \wedge \mathrm{Ga} \therefore \exists x(\mathrm{~F} x \wedge \mathrm{G} x) .
$$

So, there are good reasons for applying Frege's general statement about abstract noun-clauses to truth-ascriptions and hence for assigning to the latter the logical form of a predication.

But this logical-form proposal would not meet with Frege's approval. In our main text he reaches the tentative conclusion:

(F.12) [4] So the meaning of the word 'true' seems to be altogether sui generis. [5] May we not be dealing here with something that is not a property (Eigenschaft) in the ordinary sense at all? [...]

Less tentatively he had put the same point already in $\mathrm{SuB} 34-35$, and he repeated it unequivocally in a manuscript of 1906:

(F.13) If we say 'the thought is true', we seem to be ascribing truth to the thought as a property. If that were so, we would have a case of subsumption. The thought as an object would be subsumed under the concept of the true. But here we are misled by language. We do not have the relation of an object to a property (Wir haben nicht das Verhältnis des Gegenstandes zur Eigenschaft) [...]. (N, $210(194))$

There is no evidence whatsoever that Frege ever gave up this position. But what reason(s) did he have for rejecting the 'subsumption view' that I, like most philosophers, favour?

His argument for this rejection is what I shall call an Argument From Assertoric Force. Recall what we have read in

(F.10) So it seems that [2] nothing is added to the thought by my ascribing to it the property of truth. [3] And yet, is it not a great result when the scientist after much hesitation and laborious researches can finally say 'My conjecture is true'? [...] 
Frege's own point in [3] was not the trouble which I believe unrevealing truth-ascriptions cause for his view. In the situation described in [3], the speaker can easily replace the unrevealing truth-ascription by a revealing one: after all, it is his conjecture. Frege's concern was a quite different tension: If the use of 'true' is apparently superfluous, see [2], how can truth claims matter so much to scientists when they are bringing in the harvest of their researches? Frege might as well have posed this question by putting a revealing truth-ascription into the mouth of the scientist: Imagine an excited Goldbach writing to Euler, 'Last night I have found the proof for my conjecture: it is true that each even number greater than 2 is the sum of two primes'. (Do not be misled by the English word 'scientist': a mathematician is a Wissenschaftler, and for Frege mathematics is the Wissenschaft par excellence.) Now the revealing rephrasal of the exclamation can help us to understand how Frege tries to alleviate the tension. In Ged he repeats an argument from $S u B$ to the effect that the use of 'true' is assertively redundant, and his argument is entirely convincing as long as we stick to revealing truth ascriptions. If an utterance of an assertoric sentence is made by an actor on the stage or if it is embedded in an (assertoric) utterance of a conditional or of a disjunction, then it is not an assertion, no matter whether it contains a truth-connective or not. And an utterance which does contain a truth-connective and which is an assertion would not have lost its assertoric force if the speaker had decided not to use the truth-connective. How is the undeniable assertorical redundancy of truth frame and truth prologue, which concerns the illocutionary role of an utterance, related to their alleged propositional redundancy, which concerns the content of an utterance? The former explains the latter, Frege contends in Ged:

(F.14) An advance in science usually takes place in this way: first a thought is grasped, and thus may perhaps be expressed in a yes-no question; after appropriate investigations, this thought is finally recognized to be true. We declare the acknowledgement of truth ( $A n$ erkennung der Wahrheit) in the form of an assertoric sentence. We do not need the word 'true' for this. And even when we do use it, the real assertoric force (behauptende Kraft) does not lie in it, but in the form of the assertoric sentence; and where this form loses its assertoric force, the word 'true' cannot put it back again... This explains why it is that nothing seems to be added to a thought by attributing a property to it. (Ged, 62-63)

At the end of this passage Frege uses the language of attributing a property which he deems to be at bottom inappropriate. In $S u B$ he used the same premisses to argue against the 'subsumption view': 
(F.15) From this one may conclude that the relation of the thought to the true must not be compared with that of subject to predicate. $(\mathrm{SuB}, 34)$

Apparently, the Argument From Assertoric Force is supposed to run as follows.

(I) If truth were a bona fide property of some thought $\theta$, then grasping the thought that $\theta$ is true would be: acknowledging $\theta$ as true, and predicating truth of $\theta$ would be: putting $\theta$ forward as true.

(II) But neither of these alleged identities holds. Hence, by modus tollens,

(III) Truth is not a bona fide property of any thought.

The argument is clearly valid, and Frege has shown that premiss (II) is true. But since I cannot see any good reason for accepting premiss (I), I deny that the Argument From Assertoric Force is sound. We can think of a thought as falling under the truth concept without thereby acknowledging its truth. After all, that is exactly what happens when wonders whether the thought is true. One can predicate truth of the thought that $p$, without thereby putting that thought forward as true, i.e. without thereby asserting that $p$. After all, that is exactly what happens when one asks somebody whether that thought is true. Admittedly, the presence of the grammatical predicate in an utterance of the form 'The thought that $p$ is true' does not ensure that the utterance is an assertion (see below, \$7). Nevertheless, it might be a logical predicate that serves the purpose of subsuming a thought under the truth concept. Frege has not shown that the subsumption view is false.

It remains to be seen how attractive his alternative to this view is. (I regret to have treated it only perfunctorily in Künne (2005).)

\section{The True and The False}

In Ged Frege does not actually present his alternative view, nor did he do so in the subsequent two 'Logical Investigations'. The project was not yet completed when he died in 1925. So the $L I$, as we have them, do not keep the promise made at the end of

(F.16) [5] May we not be dealing here with something that is not a property in the ordinary sense at all? [6] In spite of this doubt I shall for the time being express myself in accordance with ordinary usage, as if truth were a property, until something more appropriate (etwas Zutreffenderes) is found. (Ged, 62) 
But actually, Frege had developed many years earlier a conception of truth that he deemed more appropriate, and there is not the slightest reason for thinking that he ever changed his mind in this respect. His preferred alternative to the subsumption view is mentioned in the continuation of (F.13) that I have so far suppressed:

(F.17) We do not have the relation of an object to a property, but that of the sense (Sinn) of a sign to its signification (Bedeutung). ( $N, 210$ (194))

Let me try to explain, and to evaluate, this conception. Here are four questions each of which is answered affirmatively by Frege:

(i) Are some assertoric sentences such that they do not only express a thought (sense) but also have a signification (Bedeutung)?

(ii) Is the signification of a sentence a truth-value?

(iii) Are truth-values objects?

(iv) Does a sentence stand to its truth-value in the same semantic relation in which the name 'Socrates' stands to the man Socrates?

In $(S u B, 33-34)$ we hear Frege say four times, Yes. It is worth going through this text sentence by sentence.

$\left(\right.$ F.18 ${ }_{a}$ ) [1] We have seen that there must always be sought a signification (Bedeutung) for a sentence whenever the signification of its components matters; and this is the case when and only when we are inquiring after the truth-value.

Here Frege summarizes the preceding argument for his answer to the first question. His argument presupposes that we already have a conception of what it is for a singular term to have a signification. If all goes well, a singular term "signifies or designates (bedeutet oder bezeichnet)" an object, and this object "may be called its signification (Bedeutung)" $(\mathrm{SuB}, 26,31) .^{20}$

${ }^{20}$ Apparently Frege wanted to use as title for the object signified a verbal noun derived from one of the two verbs which he uses interchangeably in $S u B, 31$ (He no longer does so in $(G G I, \$ 2)$. See $\$ 6$ below). He could not use the noun derived from 'bezeichnen', since a Bezeichnung is a linguistic sign. So he did the next best thing and stipulated a special use for the verbal noun 'Bedeutung.' The next best thing is not always a good thing, and the fact that the German words 'Bedeutung' and 'Sinn' are often used as stylistic variants of each other is a serious disadvantage. Clearly, Frege thought that he had obviated the imminent confusions by the way he introduced the term into his theoretical vocabulary.-He seems not to be aware of the fact that already his use of the verb 'bedeuten' as interchangeable with 
A singular term lacks signification if not all goes well, that is, if there is no object which it signifies. Now in the argument for the affirmative answer to the first question we were meant to understand 'signification' in such a way that the following two statements come out true: [a] A sentence that expresses a thought has no signification, if it contains a singular term that does not signify anything, and [b] two sentences that express different thoughts have the same signification (if any), if one can be transformed into the other by exchanging an embedded singular term for another that has the same signification.-These are not an arbitrary stipulations. Consider a complex singular term like 'the largest Moon of Vulcan': [ $\left.\mathrm{a}^{\star}\right]$ A complex singular term that expresses a sense has no signification, if it contains a singular term that does not signify anything. ${ }^{21}$ Consider a pair of complex singular terms like 'the father of Jean Baptiste Molière' and 'the father of Jean Baptiste Pocquelin': $\left[\mathrm{b}^{\star}\right]$ Two singular terms have the same signification (if any), if one can be transformed into the other by exchanging an embedded singular term for another that has the same signification. Frege is appealing here to his principle of compositionality as regards signification: the signification of a semantically complex expression is determined by the signification of its components and the way it is composed from them.

Now what does the signification of a sentence consist in? We care for a sentence's components having signification, Frege had argued in the paragraphs preceding [1], when it matters to us whether the sentence expresses a truth or a falsehood. And when we ask whether it expresses a true thought or a false one, we do what is called in [1] "inquiring after its truth-value". From here Frege goes on to answer the second question on our list:

$\left(F .18_{b}\right)$ [2] We are therefore driven into accepting the truth-value of a sentence as its signification (Bedeutung).

This is not a deductively justified step, and it is not meant to be one. On the basis of the preceding reflections one might as well say that the signification of a sentence (if it has one) is a state of affairs. The sentence 'Molière died on the stage', one could argue, represents the same state of affairs as the sentence 'Pocquelin died on the stage' (and since these sentences express true

'bezeichnen' is a possible source of confusion: In colloquial German the question, "Was bedeutet 'the inventor of bifocals'?" cannot be answered by saying 'Benjamin Franklin', but only by a translation (or by a synonymous English phrase, 'The person who invented lenses for spectacles', or some such). 'Benjamin Franklin' would, however, be a decent reply to the question "Was (wen) bezeichnet 'the inventor of bifocals'?"

${ }^{21}$ Some hard work needs to be done to protect this against prima facie counterexamples like 'this statue of Venus', 'that worshipper of Baal', 'Meinong's obsession with the round square. The complex singular term must not invoke aboutness or intentionality, but how is this restriction to be captured semantically? 
thoughts that state of affairs is a fact): cf. Künne (2005, 11-12, 116, 139, 253). And the sentence 'Vulcan has several moons' does not represent any state of affairs, not even a non-obtaining one, because 'Vulcan' is a singular term without signification. Of course, Frege could not say any of this, for, as we saw in (F.4), he identifies facts with true thoughts, and hence he would be ready to identify states of affairs with thoughts. But that might only show that he has deprived the category States of Affairs of a useful service, as Husserl and Armstrong (a rather unlikely couple, I admit) would say. Now Frege does not claim in [2] that his reply to the second question is implied by the reflections that precede it, and later on in $S u B$ he calls his answer twice a "conjecture" $(35,36)$.

[2] does not commit Frege to giving an affirmative answer to the third question on our list. After all, the term 'truth-value' might occur only in contexts of the following two types:

$(\alpha)$ Sentence $S$ has a truth-value

$(\beta)$ Sentences $S_{1}$ and $S_{2}$ have the same truth-value,

and such formulations might just serve as handy abbreviations of

$\left(\alpha^{\star}\right)$ S expresses a true thought, or $\mathrm{S}$ expresses a false thought

$\left(\beta^{*}\right) S_{1}$ and $S_{2}$ both express a true thought, or they both express a false thought.

But then no objects that are not referred to in $\left(\alpha^{\star}\right)$ or $\left(\beta^{\star}\right)$ are referred to in $(\alpha)$ or $(\beta)$.

In the continuation of our passage Frege first tries to explain what badly needs an explanation, the phrase 'the truth-value of $S$ ':

$\left(\right.$ F.18 ${ }_{c}$ ) [3] By the truth-value of a sentence I understand the circumstance (Umstand) that it is true or that it is false. [4] There are no further truth-values. [5] For brevity I call the one the True (das Wahre), the other the False (das Falsche).

Unfortunately, [3], of all things, is very confusing, and I am afraid that it is confused. Clearly Frege does not understand by the truth-value of a sentence the circumstance that makes it, or rather, that makes the thought that it expresses, true or false. Firstly, he never appeals to the notion of a truthmaker. Secondly, the circumstance that makes the thought that is expressed by 'Tallinn is the capital of Estonia' true seems to be the circumstance that Tallinn is the capital of Estonia, and that very same circumstance makes the thought that is expressed by 'Tallinn is the capital of Lithuania' false. But Frege wants to assign different truth-values to these two sentences.-There is a greater temptation to confound [3] with 
(*) By the circumstance that a sentence has a truth-value I understand the circumstance that it (expresses a thought that) is true or false.

This would be a rather round-about way of introducing the predicate ' $x$ has a truth-value. If that had been Frege's point he would have done better to drop reference to circumstances and to say simply,

(†) $x$ has a truth-value iff $x$ (expresses a thought that) is true or false.

Now this suggests that talk of truth-values is just an abbreviatory device. "It is convenient", Quine says, "to speak of truth and falsity as truth-values; thus the truth-value of a statement is said to be truth or falsity according as the statement is true or false." ${ }^{22}$ As it stands, $(\dagger)$ is fine with Frege, but if this were all he is up to it would become incomprehensible why he introduces the strange titles 'the True' and 'the False' in [5]. What he wants to elucidate in [3] is not the predicate ' $x$ has a truth-value' but singular terms of the type 'the truth-value of sentence $S$. The disjunctive component of [3] is a contracted disjunction of two open identity-sentences (along the lines of 'The favourite uncle of a girl is the brother of her father or the brother of her mother'):

(t-v) If a sentence $x$ has a truth-value at all, then the truth-value of $x$ is the circumstance that it expresses a thought which is true, or the truth-value of $x$ is the circumstance that it expresses a thought which is false.

[4] only emphasizes a consequence of (t-v), and in [5] Frege introduces the term 'the True' ('the False') as a name for what the singular term 'the truthvalue of $S$ ' signifies just in case $S$ expresses a true (false) thought. So the whole elucidatory weight lies on the shoulders of $(\mathrm{t}-\mathrm{v})$. But these shoulders are not Christophorus-like. Frege relies on our understanding singular terms of the type 'the circumstance that $p$ '. But on our ordinary understanding, the circumstance that $p$ (which may be a circumstance that must not be neglected, that has to be taken into account, etc.) is identical with the fact that $p$. But this cannot be what Frege means. For one thing, he takes facts to be true thoughts, but truth-values are certainly not thoughts. Secondly, even if you believe in a plurality of facts (as Frege does) but reject Frege's conception of facts, you will reasonably deny that (the fact that the sentence 'The Moon is round' expresses a truth) coincides with (the fact that the sentence 'Molière is dead' expresses a truth), but Frege wants the term 'truth-value' to be understood in such a way that these two sentences (like all others that express a true thought) have the same truth-value. So our ordinary understanding of the phrase 'the circumstance that $p$ ' does not help

${ }^{22}$ Quine (1952, \$2). 
us to grasp the sense which Frege wants to be connected with the singular term 'the truth-value of $S$ '. Appealing to an extraordinary understanding of that phrase would make (t-v) worse than useless.-Frege's next step is a very dubious inference:

(F.18 ${ }_{d}$ [6] Every assertoric sentence for which the signification (Bedeutung) of its words matters is therefore to be regarded as a proper name (Eigenname), and its signification (Bedeutung), if it has one, is either the True or the False.

Frege takes himself to be justified in giving a positive answer to the fourth question on our list,

(iv) Does a sentence stand to its truth-value in the same semantic relation in which the name 'Socrates' stands to the man Socrates?

And if his answer is correct then our third question is also to be answered affirmatively:

(iii) Are truth-values objects?

But one can consistently accept the claim that truth-values are objects which are designated by singular terms of the type 'the truth-value of S', while rejecting the contention that they are also designated by sentences. A philosopher, who believes that extensions are objects which are designated by singular terms of the type 'the extension of predicate P', can and should deny that the predicates whose extensions they are also designate them. So why not deny that the sentences truth-values are truth-values of stand to them in the same semantic relation in which a name stands to its bearer?

Frege answers question (iv) affirmatively because this answer is implied by his functional account of predicates. If the predicate ' $x$ is a university town' literally is what 'the square of $x$ ' literally is, namely a function-sign, then in both cases a singular term as input delivers a singular term as output: in the case of ' $\mathrm{x}^{2 \text { ' }}$ the result of inserting the numeral ' 4 ' designates a number, in the predicational case the result of inserting the name 'Tartu' designates a truth-value. As against this, I believe that predicates are only metaphorically function-signs, expressions that can usefully be compared with functionsigns. Literally the predicate ' $x$ is a university town' is an open sentence in which a position is reserved for a singular term. This Quinean characterization does not commit us to regarding the result of inserting a singular term as a singular term.

When you judge that Tallinn lies at the Baltic you acknowledge not only the existence of a town and of a sea, Frege contends, but also that of two abstract objects, named the True and the False: 
$\left(\right.$ F.18 ${ }_{e}$ [7] These two objects are acknowledged, if only implicitly (stillschweigend), by everybody who makes a judgement, who acknowledges something as true, hence even by the sceptic.

The sceptic in [7] is not the 'Pyrrhonian' sceptic (of an old legend) who refrains from making any judgement but rather a 'Cartesian' sceptic who refrains from those judgements whose contents can only be true if there is an external world or if there is more than one subject of mental states-or-acts.

Every self-styled nominalist can be expected to reject Frege's contention that each judgement commits us to those two abstract objects. Frege would register this protest as a further manifestation of the "very widespread tendency not to acknowledge as an object anything that cannot be perceived by the senses" $(F u B, 3)$. But in the vicinity of the claim in [7] there is a humble point which is not an ontological one: when one makes a judgement to the effect that $p$ one acknowledges the thought that $p$ as true, and thereby one incurs an obligation to reject the thought that not-p as false; and when one makes a judgement to the effect that $\sim p$ one acknowledges the thought that $\sim p$ as true, and thereby one incurs an obligation to reject the thought that $p$ as false. I endorse this claim. It does not imply that one cannot make a judgement unless one has mastered the concepts of truth and falsity. One can incur an obligation without being able to articulate it. In the early phases of our cognitive development we make judgements (saying in our heart, 'Lo, it is snowing'), but we do not yet have the conceptual equipment for making judgements about the contents of our judgements. We can explain to children what 'true' means by giving them instructions such as 'If you say, "It is raining", and it is raining, then what you say is true. But if you say, "It is raining", and it is not raining, then what you say is not true. Or if you say, "It is snowing", and it is snowing, then what you say is true. But if you say, "It is snowing", and it is not snowing, then what you say is not true. Got it, darling?' To understand such an explanation, the child must, of course, already understand sentences such as 'It is raining' and 'It is snowing. Whether the child 'got it' will become manifest in his or her future use of 'true'. (Cf. Künne 2005, 51f) Do we have to assume that in such lessons the child only acquires a word to express a concept that is already in his or her conceptual repertoire? I have come to think that this is (at least partially) an empirical question for developmental psychology. As an armchair psychologist who is fond of taking risks I bet that it takes children, who are pretty good at saying what the weather outdoors is like, quite a while until they become receptive to such meta-lessons. 


\section{The Omnipresence of Truth (in a Begriffsschrift)}

An essay on the topic 'Frege on Truth' is a Hamlet without the Prince of Denmark if it does not deal with the language which Frege deems to be the ideal medium for rational thinking, his ideography (Begriffsschrift). I shall consider only his mature account of this language that is to be found in his ill-starred opus magnum, Grundgesetze der Arithmetik (Basic Laws of Arithmetic). This account presupposes the view that the truth-value of a sentence is an object that is designated by that sentence.

While sentences in a language like English are primarily series of sounds, recall (F.1), sentences in an ideography are always, unsurprisingly, inscriptions. In a language like English there is no absolutely reliable indicator whereby one can recognize whether an utterance or an inscription has assertoric force. In Frege's ideography there is a special sign the presence, or absence, of which at the left-hand side of an inscription makes unambiguously clear whether the inscription is to be understood as having, or as lacking, assertoric force.

(F.19) I am not asserting anything when I merely write down an equation, but only designating (bezeichnen) a truth-value, just as I am not asserting anything when I merely write down ' 2 ', but merely designating a number. $\left(G G I, \$_{5}\right)$

Note that here it is not the sign that is said to designate something but rather the user of the sign. (By contrast, only of signs it is said in GG that they signify (bedeuten) something.) If you want to make an assertion in BS you must put a vertical stroke on the left-hand side of a series of signs, the socalled "judgement-stroke (Urteilsstrich)". Here are four examples of what an ideographic sentence, a Begriffsschriftsatz, looks like:

$$
\vdash 2+3=5 \quad \vdash 2
$$

$\vdash$ The Earth is larger than the Moon $\quad \vdash$ The Earth

While an inscriber of ' $2+3=5$ ', using this as an ideographical symbol, does not yet assert anything, but only designates a truth-value, (an inscriber of)

(F.20) ' $\vdash 2+3=5$ ' does not designate anything, but asserts something. $(F u B, 22, \mathrm{n})$

How is the horizontal part of the prefix to be understood? It follows from Frege's explanation that the horizontal stroke can be read as the predicate 'is identical with the True. ${ }^{23}$ By putting only the horizontal in front of ' $2+$

${ }^{23} \mathrm{FuB}, 21 ; G G I, \$ 5 \&$ n. 3. 
$3=5$ ' ('The Earth is larger than the Moon') you non-committally say that the truth-value of the thought that $2+3=5$ (that the Earth is larger than the Moon) is the True. If you then add the judgement-stroke you assert that this identity obtains. By placing only the horizontal in front of ' $2+3$ $=4$ ' ('The Moon is larger than the Earth') you non-committally say that the truth-value of the thought that $2+3=4$ (that the Moon is larger than the Earth) is the True. So far you have not yet committed a mistake. If you then add the judgement-stroke you falsely assert that this identity obtains. Similarly, by prefixing both horizontal and vertical to the numeral ' 2 ' (the name 'the Earth') you assert something that is false. Each and every ideographic sentence begins with the horizontal, so each and every ideographic sentence contains a truth-predicate in the guise of 'is identical with the True', and each and every thought expressed by an ideographic sentence is about the truthvalue True. So, truth is omnipresent. Of his ideography Frege can rightly say:

(F.21) What distinguishes [the truth predicate] from all other predicates is that predicating it is always included in predicating anything (es wird immer mit ausgesagt, wenn irgend etwas ausgesagt wird). ( $N$, $140(129))$

(Here the Oxford translation gets it exactly right: 'aussagen' in Frege does not mean what it often means in colloquial German: to assert, but rather: to predicate. Predications need not have assertoric force.) Or does the horizontal perhaps have a self-annihilating sense? No, it does not. Recall that the symbol '-The Earth' is well-formed: it expresses the glaringly false thought that the Earth is identical with the True. If you delete the horizontal from this symbol, the remainder no longer expresses any thought whatsoever.

The sense of a singular term, Frege famously said, is "a mode of presentation (eine Art des Gegebenseins)" of the object it designates (if it designates anything). Now if what is left of an ideographic sentence when the judgement-stroke is deleted designates a truth-value just as any (non-empty) singular term designates an object, then the sense of the truth-value name is a mode of presentation of a truth-value. So Frege cannot reasonably deny that all true thoughts can be subsumed under the concept $x$ is a mode of presentation of the True. So, by the end of the day, a subsumption view is rehabilitated even by his own lights.

Frege saw to it that truth is a topic whenever a judgment is voiced by means of an ideographic sentence. But as I said, I think that this does not at all hold whenever a judgement is voiced in our primary language. And even when the concept of truth is employed, truth is only very seldom (e.g., when philosophers meet) what our judgements are about. 


\section{Objecthood, Objectivity and Timelessness}

According to Frege, truths (and falsehoods) are the intentional objects of acts of thinking, they are in some sense objective, and they are timeless. In this section I shall scrutinize these Fregean claims about the status of truthvalue bearers and plead for injecting a dose of Husserl into Frege and for mitigating his Platonism a bit.

The theoretical use of the word 'intentional' by Brentano and his followers was based upon the colloquial use of the Latin phrase 'tendere arcum in aliquid (directing, aiming, one's bow-and-arrow at)'. Frege takes propositional acts of thinking to be directed at thoughts:

(F.22) Something in a thinker's consciousness must be aimed at the thought (auf den Gedanken hinzielen). But this should not be confused with thought itself. Similarly, [the star] Algol is different from the idea (Vorstellung) someone has of Algol. (Ged, 75a)

Let us call this the act-object model of propositional thinking. (We are not concerned with thinking of Paris or of one's lover. That is why I say 'propositional thinking.) In support of the act-object model Frege appeals to certain linguistic data:

(F.23) It may well be the case that people sometimes understand by the word 'thought' an act of thinking, but this is not always so... For do we not say that the same thought is grasped by this person and by that person? And that each person has the same thought over and over again? $(N, 147,149(136,137))$

To be sure, we do say such things. But then, we also say that two couples are dancing the same dance or that one couple repeatedly danced the same dance. Frege emphasizes:

(F.24) To think is to grasp a thought ( $N, 201$ (185), 214 (198)); (Ged, passim)

But we can hear this slogan in the same way we understand 'To waltz is to dance a waltz. Correspondingly, we can understand 'What did Ann think just now? That she would like to go to Vienna.' after the pattern of 'What did they dance a moment ago? The Strauss waltz Vienna Blood.' One feels no temptation whatsoever to say about the relation of this waltz to the many dancers who dance it what Frege is fond of saying about the relation of one and the same thought to the many thinkers who think it: that it "stands vis-àvis (gegenüberstehen) various people, like a tree". ${ }^{24}$ We can easily characterize

${ }^{24}$ Ged, 66; GG I, xvii; N, 138 (127), 145 (133), 160 (148), 214 (198). 
the structure of propositional thinking without presupposing that thoughts are its intentional objects:

(A) The thinkers $d$ and $d^{\prime}$ think the thought $\theta$ iff: For some $x$, for some $y, x$ is a thinking by $d \wedge y$ is a thinking by $d^{\prime} \wedge$ $\theta$ is the propositional content of $x \wedge \theta$ is the propositional content of $y$.

(B) $d$ thinks the thought $\theta$ at times $t$ and $t^{\prime}$ iff: for some $x$, for some $y, x$ is a thinking by $d$ at $t \wedge y$ is a thinking by $d$ at $t^{\prime} \wedge t \neq t^{\prime} \wedge \theta$ is the propositional content of $x \wedge \theta$ is the propositional content of $y$.

This act-content model is by no means alien to Frege:

(F.25) By a thought I understand not the subjective performance of thinking but its objective content (objectiver Inhalt), which is capable of being the common property of many thinkers. $(\mathrm{SuB}, 32, \mathrm{n}$.)

The thought that is expressed by 'Each even number greater than 2 is the sum of two primes' is designated by various singular terms, such as its nickname 'Goldbach's Conjecture' and nominalizations of any sentence expressing it. So thoughts are objects-in the broad Fregean reading of this term under which everything that is designated by a singular term is an object. (Under this reading, waltzes are objects, too.) Hence it is false to take Frege's third realm, that is, the realm of senses, and the realm of significations (Bedeutungen) to be disjoint, as even Dummett often does. Goldbach's Conjecture, like any other object, does belong to the realm of significations, although it is not the signification of a sentence. But the fact that thoughts are objects is not a good reason for claiming that propositional thinking is directed towards thoughts as its intentional object. Of course, like anything else, a thought can also become the intentional object, the topic, of an act of thinking. If I judge that Goldbach's Conjecture is well-known to mathematicians, one thought, sc. Goldbach's Conjecture, is the topic of my thinking and another thought, sc. the thought that Goldbach's Conjecture is well-known to mathematicians, is the content of my thinking. And if I judge that (the thought that each even number greater than 2 is the sum of two primes) is well-known to mathematicians, then one thought is both the intentional object of my thinking and a proper part of its content but another thought is its complete content (cf. Künne 2005, 259).

The act-content model ensures that one and the same thought can be thought repeatedly and by more than one thinker, but it leaves open whether the thought $\theta$ might exist even if no propositional thinking (in whatever 
mode) ever occurs. But the act-object model does not guarantee the latter kind of independence either. My copy of Frege's GG can be perceived by many people, and it can be perceived more than once by the same perceiver, and yet my copy of $G G$ does not exist in a possible world in which no thinking and no writing ever takes place. In this respect thoughts might be more similar to books than to trees. They might be what Husserl called bound idealities (as opposed to free idealities). ${ }^{25}$ The argument

(1) There is no thinker $x$ such that the existence of thought T depends on the existence of $x$. Therefore,

(2) the existence of $\mathrm{T}$ does not depend on there being any thinker

is no more valid than the argument

$\left(1^{\star}\right)$ There is no $\log x$ such that the existence of Ben's log hut depends on the existence of $x$. Therefore,

$\left(2^{*}\right)$ the existence of Ben's log hut does not depend on there being any $\log$.

Without being individually dependent on the existence of a particular thinker, each thought could be generically dependent on there being thinkers. ${ }^{26}$ Let us stipulate

$x$ is subjective $=_{D f} x$ is a mental act-or-state, or $x$ consists of mental acts-or-states

$x$ is objective $=_{D f} x$ is not subjective

$x$ is super-objective $=_{D f}$ The existence of $x$ does not depend on there ever being any mental acts-or-states.

This allows us to classify judgements, beliefs and all other mental acts and states as subjective and thoughts as objective, just as Frege wants them to be classified, but it also allows for a distinction in the realm of the objective: trees and mountains are super-objective, while books and string-quartets are not. This distinction makes one wonder whether thoughts are really superobjective, as Frege maintains. This claim might be an overreaction against those who take thoughts to be subjective, and I think it is.

Frege argues:

${ }^{25}$ Husserl $(1948,321)$.

${ }^{26}$ On the relevant notions of dependence see Peter Simons (1987, Ch. 8.3) 
(F.26) In order to be true, thoughts-e.g. laws of nature-not only do not need to be acknowledged by us [as true]: they do not even have to be thought by us... We conclude from this that these thoughts ... are principally independent of our thinking (überhaupt von unserem Denken unabhängig). ( $N, 144-145$ (133))

I do not think that the personal pronoun matters in this argument. Frege hardly wants to allow for the possibility that the truth of a law of nature, say, though not dependent on our, or on human, thinking, may be dependent on some thinking going on in some corner of the universe. I take Frege's 'we' to embrace all thinking beings. Furthermore, if the conclusion is to have any chance of following from the premiss, the premiss cannot allow for the possibility that the truth of a law of nature, say, though not dependent on its being thought by anyone, is dependent on some thought or other being thought. The truth-value of the thought that water contains oxygen, for example, only depends on the chemical composition of water, and the chemical composition of water does not depend on anyone ever thinking anything. But then, how convincing is the following Independence Argument?

(Indep)(Pr) The truth of the true thought that water contains oxygen does not depend on anyone ever thinking this or any other thought. So,

(C) the existence of the true thought that water contains oxygen does not depend on anyone ever thinking anything.

Is (Indep) valid? Consider an analogous argument. Let $J$ be an act of judging that water contains oxygen. Following Bolzano and Husserl, we can call an act of judging correct (richtig) iff its content is true. The correctness of $J$ does not depend on anyone's ever thinking anything, but only on the chemical composition of water. But the analogous conclusion is obviously false: the existence of $J$ is by no means independent of anyone ever thinking anything. So why should (Indep) justify its conclusion? The conclusion may be true, but it does not follow from the premiss.

According to Frege, the copula in an utterance of the form 'The thought that $p$ is true' is only grammatically but not logically tensed: it does not carry a reference to the time of the utterance. If a true thought were always true then it would a fortiori now be true, but when Frege is careful he always insists that truth is timeless, atemporal (zeitlos), not omnitemporal. He is not always careful:

(F.27) [T]he laws of nature, and likewise those of mathematics have always held good (gelten von jeher) and not just since they were discovered. $(N, 144$ (133)) 
The verb 'gelten' is here just a stylistic variant of 'wahr sein'. I quote this remark in spite of its sloppiness concerning timelessness vs. everlastingness, because Martin Heidegger, unwittingly, contradicted it three decades later:

(H) Newton's Laws, the Law of Contradiction, any truth whatsoever is true only as long as there is Dasein... Before Newton's laws were discovered they were not true... Before him they were neither true nor false... They became true through Newton. (Sein und Zeit (1927), $\$ 44 . c)$

According to $(\mathrm{H})$, nothing whatsoever was true before the dawn of human existence; whatever is true was neither true nor false before it became known to be true, and it will again become neither true nor false with the dusk of human existence. (This is an extremely implausible version of alethic antirealism: more sober anti-realists tend to say that something is true only if it can in principle be known to be so.) Frege has refuted (H) long before it was written:

(F.28) The astronomer can apply a mathematical truth in the investigation of long past events which took place when ...no-one had yet recognized that truth. He can do this because the truth of a thought is timeless. $(\mathrm{Ged}, 74)$

If the laws that are used by astronomers in their explanations were neither true nor false at the time when the events to be explained occurred, how can their explanations work? Similarly, if the laws that are used by astronomers in their prediction of an eclipse of the sun, say, will be neither true nor false at the time (after the extinction of Dasein) when the predicted eclipse is supposed to take place, how is it that such predictions have a good chance of being true?

Now Frege says of true thoughts not only that they are timelessly true, he also claims that they are timeless (not in time):

(F.29) The thought that we have formulated in the Pythagorean theorem is timelessly true. (Ged, 69)

(F.30) The thought that we formulate in the Pythagorean theorem is surely timeless. $(\mathrm{Ged}, 76)$

Do not be misled by the example. What Frege says about the geometrical theorem he is ready to say about any truth, and he does say it. Does the timelessness of truth imply that truths, that is, truth-bearers are timeless? To be sure, if thoughts are not in time then they are not subjective, and Frege is keen to deny that they are subjective. But if they are timeless they are 
not only objective, they are super-objective. So once gain, this may be an overreaction on Frege's part, and I think it is. Or are we obliged to accept truths being timeless as soon as we have endorsed truth's being timeless? Is the following Atemporality Argument valid?

(Atemp)(Pr) The thought $\theta$ is timelessly true. So,

(C) the thought $\theta$ is timeless.

Consider an analogous argument. Let $J$ be an act of judging, and let us call an act of judging correct (richtig) iff its content is true. Now it is as reasonable to say of the copula in ' $J$ is correct' that it is logically untensed, as it is reasonable to say this about the copula in ' $\theta$ is true. But the analogous conclusion is obviously false. Like any other act, $J$ is certainly not timeless: it takes place at a certain time. So why should (Atemp) justify its conclusion? The conclusion may be true, but it does not follow from the premiss. So I grudgingly admit that in one respect Heidegger may well be right: perhaps there are true (as well as false) thoughts only in that epoch in the history of the universe in which there are thinkers around. This does not at all imply that they are only true in that epoch. If the copula in 'is true' is no more logically tensed than the ' $=$ ' in an equation, then 'true at such-and-such a time' applies to nothing.

\section{Bibliography}

Bermúdez, J. (2001). Frege on thoughts and their structure, Logical Analysis and History of Philosophy 4: 87-105.

Bolzano, B. (1837). Wissenschaftslehre, Seidel, Sulzbach.

Davidson, D. (1984). Inquiries into Truth and Interpretation, Oxford Uuniversity Press, New York.

Dummett, M. (1991a). Frege and Other Philosophers, Clarendon Press, Oxford.

Dummett, M. (1991b). Frege: Philosophy of Mathematics, Duckworth, London.

Dummett, M. (1993). Origins of Analytical Philosophy, Harvard University Press, Cambridge Mass.

Dummett, M. (1997). Bolzano and Analytic Philosophy, Rodopi, chapter Comments on Wolfang Künne's Paper, pp. 241-248.

Frege, G. (1879). Begriffsschrift. 
Frege, G. (1891). Funktion und Begriff.

Frege, G. (1892). Sinn und Bedeutung.

Frege, G. (1893). Grundgesetze der Arithmetik, Vol. I.

Frege, G. (1918). Der Gedanke.

Frege, G. (1923). Gedankengefüge.

Frege, G. (1969). Nachgelassene Schriften.

Frege, G. (1979). Posthumous Writings, Blackwell, Oxford.

Frege, G. (1984). Collected Papers, Blackwell, Oxford.

Husserl, E. (1948). Erfahrung und Urteil, Meiner, Hamburg.

Kant, I. (1929). Kritik der reinen Vernunft, 2nd edn, Macmillan, Trans. London.

Künne, W. (2005). Conceptions of Truth, Clarendon Press, Oxford.

Quine, W. (1952). Methods of Logic, Routledge, London.

Rumfitt, I. (1994). Frege's theory of predication, Philosophical Review 103: 599-637.

Schnieder, B. (2004). "nach Leibniz' Gesetz ergibt sich...”. Über einen verbreiteten Fehl-schluss, in M. Siebel and M. Textor (eds), Semantik und Ontologie, Ontos, Frankfurt/M, pp. 223-248.

Simons, P. (1987). Parts, Oxford University Press.

Williamson, T. (2006). Conceptual truth, Proceedings of Aristotelian Society SV 80: $1-41$. 